\title{
The logic of divisively asymmetric contests: respect for ownership and the desperado effect
}

\author{
ALAN GRAFEN \\ Animal Behaviour Research Group, Zoology Department, Oxford University, South Parks Road, \\ Oxford OX1 3PS, U.K.
}

\begin{abstract}
It is current orthodoxy in biological game theory that in animal contests with easily recognized asymmetries between the contestants, an asymmetry will be used to settle the dispute. Here it is argued that, if the winning of contests plays a major part in gaining reproductive success, an individual will not be selected to respect an asymmetry which will place it always in the losing role. Asymmetries that create consistent losers of this sort are termed divisive asymmetries. Divisive asymmetries cannot be used to settle important contests in an evolutionarily stable way because the consistent losers will have no incentive to respect them.
\end{abstract}

\section{WHEN BOURGEOIS MAY NOT BE AN ESS}

One of the most widely accepted successes of the Evolutionarily Stable Strategy (ESS; Maynard Smith \& Price 1973; Maynard Smith 1982) approach to our understanding of animal behaviour is the explanation it provides of the observation that in fights between territory holders and intruders, the territory holders generally win. The explanation is that ownership is used as an asymmetry to settle the dispute in favour of the owner. The main result from ESS theory supporting this explanation is that even in the unlikely case that ownership was uncorrelated with fighting ability and with the value of the territory to an individual, ownership could still be used as an arbitrary asymmetry to settle disputes in favour of the owner. How much more likely it is, then, that ownership will be used to settle the dispute without real fighting when it is, in fact, correlated with fighting ability or with the value of the territory to an individual. This is the argument advanced by Maynard Smith \& Parker (1976).

My main purpose here is to argue that in an important class of cases, which can be roughly characterized as those involving long term territories, ownership cannot be used as an arbitrary asymmetry, or even, to an extent, as a correlated asymmetry. The argument will apply more generally to all 'divisive asymmetries', a term I shall define later. So far as territorial disputes are concerned, this will leave us with the simpler argument that if owners do win fights against intruders, then it is because the owners are bigger and better fighters. Various comments that follow naturally will be made after the argument has been given.

Maynard Smith \& Parker (1976) model a territorial dispute as an asymmetric hawk-dove game. That is, each contestant knows its role (owner or intruder), and has a choice of two strategies called $\mathrm{H}$ and $\mathrm{D}$. The sense in which a contestant knows its role is that it is allowed to make its choice of strategy depend on its role, permitting for example a strategy that Maynard Smith \& Parker call 'Bourgeois': if owner play H, if intruder play D. They showed that Bourgeois is an ESS when $V$, the value of winning the fight, is less than $\mathrm{C}$, the cost of losing the fight. The standard payoffs for the hawkdove game are represented as: to $\mathrm{H},(V-C) / 2$ against $\mathrm{H}$, and $V$ against $\mathrm{D}$; to D. 0 against $\mathrm{H}$, and $V / 2$ against $\mathrm{D}$.

While the logic of Maynard Smith \& Parker's argument is not disputed here. they neglect an interesting property of $V$ and $\mathrm{C}$ that is highly relevant to the likelihood of the condition being fulfilled. The benefits of winning and costs of losing are likely to depend on the fighting rules adopted by the population, for the following reasons. In a population that respects ownership, the winner of a fight is likely to retain the territory for a long time: while in a population in which territories change hands frequently, the winner of a fight is likely to lose it again soon. The value of winning is therefore higher in a population that 
respects ownership and lower in a population that does not.

The cost of losing may also depend on the fighting rules adopted by the population. The cost is the difference in expected future reproductive success (EFRS) made by playing $\mathrm{H}$ and losing, compared with playing D (i.e. retreating). In a population in which reproduction can take place only by territory holders, and in which ownership is respected, and in which vacant territories are rare, an individual who is not an owner and follows the common convention of respecting ownership will reproduce only in the unlikely event it discovers a vacant territory. Playing $\mathrm{H}$ and losing, even if it meant certain death, could not be much worse than this small chance of reproduction. This has the important implication that in the limit, as vacant territories become more and more rare, the cost of fighting becomes zero. This of course renders unfulfillable the condition $V<C$ for the Bourgeois strategy to be an ESS. This means that Bourgeois is invadable by a strategy that plays $\mathrm{H}$ both as owner and as intruder. The logic of playing $\mathrm{H}$ as intruder is simply that the intruder has nothing to lose and much to gain.

In a population that does not respect ownership, on the other hand, the cost of fighting could be high, as the EFRS of a loser will include reproduction on the reasonable chance that the loser today will be a territory holder tomorrow.

How do these considerations affect the evolutionary stability of Bourgeois? A population dominated by Bourgeois will be a population that respects ownership, and we have seen that this tends to increase $V$ and to decrease $C$. Both of these tendencies make the stability condition for Bourgeois, $V<C$, less likely to be fulfilled. In the particular case where there are no vacant territories and all reproduction is by territory holders, we have already seen that the stability condition cannot be fulfilled. We can express this by saying that under plausible conditions, when the dependence of Vand $C$ on population strategies is taken into account as they certainly should be, Bourgeois is not an ESS.

The assumptions required to make the Bourgeois strategy not an ESS are (1) territories last for some time, (2) reproduction requires a territory, and (3) vacant territories are rare. Small violations of these conditions will have only a small effect on the arguments. Note too that the same conditions for fighting apply to the owners as to the intruders.
When vacant territories are common, and it becomes not worthwhile for an intruder to fight, it also becomes not worthwhile for a territory holder to fight. In both cases, it is better to avoid the risk of injury and depend on obtaining a vacant territory soon.

Davies (1978) gives an example of short-term territories, in which speckled wood butterflies, Pararge aegeria, occupy patches of sunlight on the ground in a wood. Even if ownership was respected in this case, possession of a territory now does not guarantee possession of the same territory in $2 \mathrm{~h}$ time because the territory may well have disappeared. Respect for ownership will therefore not make $V$ very high. Equally, non-possession of a territory now does not make so very unlikely the possession of a territory in $2 \mathrm{~h}$ time, because new territories are continually being created. Respect for ownership will not therefore make $C$ very low. It is probably also the case that not all reproduction takes place on territories. This example is a clear case where the Bourgeois strategy may still be an ESS despite the arguments given above, through violation of all three assumptions.

It is worth pointing out that not only is the use of ownership as an arbitrary asymmetry ruled out under the three assumptions, but also the use of ownership as a correlated asymmetry in which, for example, owners are better at fighting than intruders. A non-owner with the prospect of no reproduction if $\mathrm{D}$ is played is going to play $\mathrm{H}$ even if it has only a small chance of winning. Owners will therefore have to fight to retain their territories, and not merely persuade intruders by displaying that the intruder would very likely lose a fight.

I have now finished the main argument about ownership, and wish to go on to various topics that arise from it. First, I shall justify and amplify the assertions made earlier about how costs and benefits should be interpreted in game theory models, stressing the possible frequency dependence of costs and benefits. That payoffs should have something to do with number of offspring is unsurprising, but to my knowledge, no one has previously considered exactly how payoffs should be calculated from information about offspring. Second, I shall extend the scope of the argument to include all divisive asymmetries (shortly to be defined), of which ownership is only one example. Third, I shall give a brief account of why territory owners may seem to win rather more fights against intruders than they really do. Fourth, I shall consider 
whether ESS models really do explain restraint in animal aggression.

\section{HOW PAYOFFS ARE DERIVED FROM OFFSPRING NUMBER}

The maxim 'payoffs should be offspring' has no doubt gained ready acceptance. My purpose here is to make this notion more precise, and then to provide an example to show how this more precise notion can be applied to an ESS model, so that the terms which are elementary in the model are defined in terms of numbers of offspring. Game theory assumes that individuals maximize payoffs, while the theory of natural selection entitles us to assume that individuals maximize number of offspring. We therefore decide what costs and benefits mean according to the principle that the strategy that maximizes payoff must also maximize number of offspring. This means that payoff must equal number of offspring, possibly with a constant subtracted, and possibly multiplied by a positive number. The constant and positive number may be called scaling constants, since they merely change the scale on which payoffs are measured. Effectively, the entries in the payoff matrix should be the expected future reproductive success (EFRS) of an individual in the circumstances defined by its own strategy and that of its opponent. This procedure answers the question of what in principle the entries in the payoff matrix are. It can also tell us whether the entries in the payoff matrix depend on the frequencies of strategies in the population.

This principle can be illustrated by application to the War of Attrition of Maynard Smith (1974). Individuals maximize their payoff, which comprises the benefit from winning if they win (let this be $B(t)$, allowing it to depend on the contest duration), and their costs for fighting up to the duration of the contest whether they win or not (let this be $C(t)$, and note that this makes the cost function of the War of Attrition models $c(t)=\mathrm{dC}(\mathrm{t}) / \mathrm{dt})$. Now let us define $N_{\mathrm{l}}(t)$ as the EFRS if the individual loses after a contest duration of $t$, and $N_{\mathrm{w}}(t)$ as the EFRS if the individual wins after a contest of duration $t$. Then, since individuals must maximize their EFRS, which consists of $\mathrm{N}_{\mathrm{w}}(\mathrm{t})$ if they win and $\mathrm{N}_{\mathrm{l}}(\mathrm{t})$ if they lose, and using $\alpha$ and $K$ as scaling constants,

$$
\begin{aligned}
& N_{\mathrm{l}}(t)=K-C(t) / \alpha \\
& N_{\mathrm{w}}(t)=K+B(t) / \alpha-C(t) / \alpha
\end{aligned}
$$

and this yields after a simple manipulation

$$
\begin{aligned}
& c(t)=\mathrm{d} C(t) / \mathrm{d} t=-x \mathrm{~d} N_{1}(t) / \mathrm{d} t \\
& B(t)=\alpha\left\{N_{\mathrm{w}}(t)-N_{\mathrm{l}}(t)\right\} .
\end{aligned}
$$

These expressions define what the costs and benefits mean in the War of Attrition model. In words, the benefit of winning after duration $t$ is the difference in EFRS between winning at $t$ and losing at $t$. The cost of fighting per unit time is the difference per unit time made to the EFRS conditional on losing. This provides an example of how to work out the meaning of costs and benefits in a game theory model. For attempts to measure costs and benefits in modelling the War of Attrition without apparent knowledge of this result, see Riechert (1978, 1979) and Parker \& Thompson (1980). It may be objected that the EFRS conditional on winning and losing is very difficult to measure. This is true, and it forces on us the corollary that the costs and benefits in the War of Attrition are very difficult to measure. But we cannot really expect to get away without measuring (or estimating, or making assumptions about) such obviously important quantities as the effects of strategies on expected future number of offspring, in an evolutionary model.

\section{DIVISIVE ASYMMETRIES}

I now move on to extend the argument to a wider class of asymmetries. An intruder plays $\mathrm{H}$ because it has nothing to lose when the common strategy is Bourgeois. The reason it has nothing to lose is that it will always be on the losing side if it plays $\mathrm{D}$. This also applies to an asymmetry based on adult size. The smallest individual will always lose fights if size is respected, and if the analogue of the three conditions listed above holds, then this is enough to show that respect for the size asymmetry cannot be an ESS. For size, the analogous condition would be that all reproduction is performed by winners of fights. The analogues of duration of ownership and rarity of vacant territories are automatically satisfied if we assume that adult size is fixed. The crucial feature of an asymmetry that creates the 'desperado effect', leading to the undermining of the stability of respect for the asymmetry, is that respect for the asymmetry creates a class of individuals which will always be on the losing side of 
the asymmetry. I suggest that these may be called divisive asymmetries.

An example of an undivisive asymmetry is age. Although younger individuals will always lose to the individuals that are older than they, there will come a time when they themselves are old and younger individuals lose to them. This prevents the desperado effect, because by fighting an individual risks injury and death, and if it dies it will lose the reproduction it can expect to gain when it is older. There is no individual that is guaranteed to be always on the losing side of the asymmetry. Settling a dispute in favour of the young is not stable, however. This is because once old an individual will for the rest of its life be on the losing side of the asymmetry, and will have no incentive not to risk injury and death in fights.

The meaning of divisive asymmetry is then perhaps better expressed as follows: an asymmetry is divisive if respect for it creates a class of individuals that are from some point of their lives bound to be always on the losing side of the asymmetry. The logical source of the from some point of their lives' is the assumption that in a fight they risk the reproduction remaining to them from that point in their lives through the possibility of injury.

\section{WHY OWNERS MAY IN FACT WIN MORE FIGHTS}

The next point is why, in view of the arguments given above, territory owners win fights against intruders. This is, of course, a genuine biological problem rather than a matter that can be settled by algebra. However, thinking in game theory terms about the behaviour of non-owners does suggest possible reasons. In trying to find a vacant territory efficiently, an animal must provoke owners into showing themselves quickly, and then it must leave. Having decided it must fight for a territory, an animal may assess its chances against various opponents by making exploratory sallies. Both of these activities will give the appearance of an owner defeating an intruder. The all-out fight against the weakest owner will therefore be much outnumbered in the observer's notebook by what appear to be conventionally settled contests, even though they are but part of a single, consistent policy, culminating in a real fight. A model capturing a number of aspects of this strategy for non-owners is given by Parker (1974), and it is interesting to note that in the escalated fights that did occur in his model, ownership itself conferred no advantage. So we see how a sensible strategy on the part of a nonowner, which ultimately involves escalation when necessary to a fight in which ownership is unimportant, can give the appearance of respect for ownership.

The example of the speckled wood butterfly given by Davies (1978) was given as a case where Bourgeois could be an ESS. The foregoing discussion suggests that the intruding butterflies are merely seeking information about whether a given sunny spot is occupied or not, and that if they could detect occupation from further away the intruders would never intrude. So even when the Bourgeois strategy is an ESS, and is at work in a population, the natural biological interpretation is that the intruder is seeking information and not a fight. After all, why should a non-owner approach an owner if the conventional outcome is inevitable and known to them both beforehand? The reason the confrontation takes place at all is that the nonowner was hoping to find something else in the territory: either the absence of an owner, or information about the likely fighting ability of the owner.

\section{ARE LARGE CONTEST COSTS PAID IN TERRITORIAL DISPUTES?}

Next I consider one of the ways in which ESS theory is supposed to have improved our understanding of animal conflicts. It is widely believed that ESS theory has provided an alternative explanation of restraint in animal fighting, so rendering unnecessary in one respect ideas of group selection. In the simplest ESS games (the hawk-dove game and the simple War of Attrition) there is restraint in the sense that animals do not automatically fight as hard as possible in every case; but on the other hand, the contest costs suffered are equal in magnitude to the value of winning. Whether these models predict restraint in fighting therefore depends on one's initial expectations; they predict much more fighting than would be advantageous for the population as a whole. The use of ownership as an asymmetry, however, seemed a much clearer case of ESS theory predicting restraint. How is this affected by the unsettling of the Bourgeois ESS above? I believe it is affected quite strongly. The 
three conditions, together with the original stability condition of Maynard Smith \& Parker (1976), under which Bourgeois fails to be an ESS can be summarized by saying that Bourgeois can be an ESS only in fights whose outcome is not of great importance to the animals. Maynard Smith (1982) cites the example of male lions settling disputes over access to oestrous females by the Bourgeois principle. While access to oestrous females in total is obviously of supervening importance for a male lion, the outcome of one fight would be access to only one oestrous female. We expect animals to fight seriously over long-term territories, even when they incur risks of injury and death.

\section{THE STATUS OF THE BOURGEOIS PRINCIPLE}

The extent to which the Bourgeois principle is overthrown by these arguments about divisive asymmetries depends on which aspects are considered. It remains true that the fact of ownership can be a potent force in animals' lives, and that the day to day rules followed by animals may well show a 'respect for ownership'. Settling potential disputes (mainly without any aggression or appearance of a dispute) over comparatively unimportant matters may well proceed by ownership. From this point of view, my arguments leave the Bourgeois principle intact.

However, some aspects of the Bourgeois principle are affected. We have seen that when Bourgeois is the ESS, conflicts can occur only by accident, because there is no sense in an intruder beginning a fight it knows in advance it will lose. The Bourgeois principle is therefore irrelevant to a study of real fights, and cannot be used to explain why owners win them. That, if true, is presumably because owners are good at fighting. Another aspect is to ask: how is it determined which individuals own territories? The Bourgeois principle suggests that the answer is luck or chance; but we have seen that the appearance of the Bourgeois strategy is quite consistent with a situation in which real fights decide ownership. Or, we can ask: why do territories change hands? The Bourgeois principle suggests only when an individual abandons its territory; the revision given above suggests that territories change hands because of real fights. Finally, we can ask, how large are the total contest costs paid in fights over territories, compared to the value of those territories? The Bourgeois principle suggests there will be no contest costs, and this is an important part of its appeal. Our revision suggests there will be contest costs that are roughly proportional to the number of the dispossessed. In this more blood and guts world, the territories are held by bigger and better individuals, and it is important to distinguish between respect for ownership and respect for owners. Ownership can therefore play an important part in animals' lives, mainly in the avoidance of disputes and the appearance of deference to owners; but in understanding real fights, which individuals hold territories, why territories change hands, and whether contest costs are incurred in fights over territories, the Bourgeois principle can be misleading.

In conclusion, Maynard Smith \& Parker (1976) proposed that territorial disputes are settled in favour of the owner because ownership can be used as an arbitrary asymmetry to avoid contest costs. I have argued that ownership of a long-term territory is a divisive asymmetry, respect for which creates a set of 'desperados', for which the cost of fighting when correctly calculated turns out to be very small, leading to the evolutionary instability of respect for ownership. The argument applies more generally to all divisive asymmetries, which can include adult size. The use of asymmetries to settle conflicts will often cause the costs and benefits of fighting to depend on the frequencies of strategies in the population, and at least in the cases considered here this has important consequences for the biological conclusions to be drawn from the models.

\section{ACKNOWLEDGMENTS}

I am grateful for helpful comments on the manuscript from Mark Ridley, Marian Dawkins, Paul Harvey, Tim Guilford, John Krebs and John Maynard Smith.

\section{REFERENCES}

Davies, N. B. 1978. Territorial defence in the speckled wood butterfly (Pararge aegeria): the resident always wins. Anim.. Behav., 26, 138-147.

Maynard Smith, J. 1974. The theory of games and the evolution of animal conflicts. J. theor. Bid., 47, 209221.

Maynard Smith, J. 1982. Evolution and the Theory of Games. Cambridge: Cambridge University Press. 
Maynard Smith, J. \& Parker, G. A. 1976. The logic of asymmetric contests. Anim. Behav., 24, 159-175.

Maynard Smith, J. \& Price, G. R. 1973. The logic of animal conflict. Nature, Lond., 246, 15-18.

Parker, G. A. 1974. Assessment strategy and the evolution of fighting behaviour. J. theor. Biol.,47, 223-243.

Parker, G. A. \& Thompson, E. A. 1980. Dung fly struggles: a test of the war of attrition. Behav. Ecol. Sociobiol., 7, 3744 .
Riechert, S . E. 1978. Games spiders play: behavioural variability in territorial disputes. Behav. Ecol. Socio biol., 3, 135-162.

Riechert, S. E. 1979. Games spiders play: II. Resource assessment strategies. Behav. Ecol. Sociobiol., 6, 121128 .

(Received 21 October 1985. revised 7 March 1986, MS. number 2762) 